\title{
Laser-Based Microscopic Approaches: Application to Cell Signaling in Environmental Lung Disease
}

BioTechniques 31:880-894 (October 2001)

\author{
D.J. Taatjes, C.J. Palmer, \\ C. Pantano, S. Buder- \\ Hoffmann, A. Cummins, \\ and B.T. Mossman \\ University of Vermont College \\ of Medicine, Burlington, VT, \\ USA
}

\section{INTRODUCTION}

Advances in cell-imaging techniques and instrumentation are invaluable in deciphering the responses of cells and tissues to noxious agents in the environment (21). These approaches can be used to identify lesions, affected cell types, and structural alterations in cells during and subsequent to toxic exposures. Moreover, they enable an understanding of the cellular mechanisms involved in the initiation and pathology of environmental diseases as well as repair or adaptation (17).

One area of contemporary interest is the role of cell signaling pathways that may be elicited at the cell membrane by inhaled environmental agents such as asbestos, silica, or airborne particulate matter $(23,27)$. These insoluble particulates must interact via receptor-dependent or -independent mechanisms with the plasma membrane before uptake by alveolar macrophages or epithelial cells that line the respiratory tract (18). With advances in molecular probes and antibodies that are specific to phosphorylated (i.e., activated) signaling proteins, cell and molecular biologists now have the capability to document signaling events and genes transactivated by signaling proteins. In addition, the temporal patterns and causal relationships of these initiating events to the development of phenotypic responses of cells to toxic agents can be determined.

Programmed cell death (apoptosis), changes in cell cycle kinetics, and increases in DNA content that indicate unscheduled DNA synthesis or prolifera- tion are functional responses occurring in lung epithelium and other cell types after exposure to several inhaled toxicants, including oxidants. The mitogenactivated protein kinases (MAPKs), including the c-Jun-N-terminal kinases (JNKs) and extracellular signal-regulated kinases (ERKs), have been linked causally to the development of apoptosis, cell proliferation, and transformation of a number of cell types (1). These signaling cascades cause transactivation and increased expression of the fos/jun early response protooncogenes that comprise the activator protein-1 (AP-1) transcription factor. In this article, we first describe multifluorescence techniques using confocal scanning laser microscopy (CSLM) and laser scanning cytometry (LSC) to document increases in phosphorylated ERKs (pERK) in lung epithelial cells in vitro and in lung tissue after inhalation of asbestos. We then show LSC methods for the detection of cell cycle alterations and apoptosis by asbestos or the oxidative stress-inducing agent, hydrogen peroxide $\left(\mathrm{H}_{2} \mathrm{O}_{2}\right)$, as well as LSC analysis of transfection experiments, supporting a causal role of ERKs in lung epithelial cell apoptosis by oxidative stress. Lastly, we present data showing the successful isolation of distal bronchioles from the lungs of mice using laser capture microdissection (LCM) and the extraction of total RNA from these epithelial cells. The longrange goal of these studies is the application of LCM combined with quantitative real-time PCR to determine possible increases of fos/jun family mRNA levels after inhalation of asbestos. 


\section{MATERIALS AND METHODS}

\section{Preparation Protocols of Tissues and Cells for CSLM and LSC}

Experiments were performed with sections from mouse lung and with cultured pulmonary epithelial cell lines.

Mouse model and tissue preparation. C57B1/6 male mice were obtained from the National Institutes of Health (Bethesda, MD, USA) and housed in animal care facilities approved by the American Association for Accreditation of Laboratory Animal Care and operated under the supervision of the Institutional Animal Care and Use Committee of the University of Vermont. Some animals were exposed to NIEHS reference samples of crocidolite asbestos for $6 \mathrm{~h}$ per day, 5 days a week for 30 days as previously described (24).

For CSLM studies, the animals received a lethal dose of pentobarbital, and the chest cavities were opened. The lungs were instilled with PBS, followed by infusion of $4 \%$ paraformaldehyde in PBS at a constant pressure of $14 \mathrm{~cm}$ water. The lungs were removed and immersed in the same fixative overnight at $4{ }^{\circ} \mathrm{C}$, followed by rinsing with PBS and infusion with O.C.T. embedding compound (Tissue $\mathrm{Tek}^{\circledR}$; Sakura Finetek USA, Torrance, CA, USA) in a plastic cryomold. The lung pieces were then snap-frozen by plunging into liquid nitrogen-cooled isopentane. The frozen blocks were stored at $80^{\circ} \mathrm{C}$ until sectioning.

For LCM studies, lungs were removed from animals as described above, but without exposure to fixative. The unfixed lungs were rinsed with PBS, infused with O.C.T. embedding compound, snap-frozen, and stored as above.

Immunofluorescence detection of pERK in mouse lung. Frozen sections (7-10 $\mu \mathrm{m}$ thick) were cut at $-23^{\circ} \mathrm{C}$ with a stainless-steel blade on a MICROM Microtome Cryostat (MICROM Laborgerate $\mathrm{GmbH}$, Walldorf, Germany) and stored at $-80^{\circ} \mathrm{C}$ until use. For immunostaining, the sections were warmed to room temperature and placed into PBS. The sections were briefly immersed in pure methanol for $10 \mathrm{~min}$ at $-20^{\circ} \mathrm{C}$, followed by permeabilization with $1 \%$ Triton ${ }^{\circledR} \mathrm{X}-100$ in PBS for 15 min at room temperature. Following two washes with PBS, the sections were treated with $1 \%$ SDS in PBS for 5 min at room temperature to enhance antibody staining $(5,28)$. After two rinses with PBS, the sections were rinsed three times (20 min each) in 1\% normal goat serum as a blocking reagent. The sections were then incubated overnight at $4^{\circ} \mathrm{C}$ with a cocktail of two primary antibodies: (i) polyclonal rabbit anti-pERK [recognizes both p44 (ERK1) and p42 (ERK2); New England Biolabs, Beverly, MA, USA] and (ii) rat anti-mouse Mac3 (recognizes macrophages; BD Biosciences, San Jose, CA, USA).

After rinses with $\mathrm{PBS}(3 \times 5 \mathrm{~min})$, the sections were covered with a biotinylated goat anti-rabbit IgG (Vector Laboratories, Burlingame, CA, USA) for $1 \mathrm{~h}$ at room temperature, rinsed $3 \times$ 5 min with PBS, and then incubated for $1 \mathrm{~h}$ in the dark at room temperature with a cocktail of two fluorescinated probes: (i) a streptavidin Alexa ${ }^{\mathrm{TM}} 568$ conjugate and (ii) an Alexa 488 goat anti-rat IgG conjugate (both from Molecular Probes, Eugene, OR, USA). Finally, the sections were rinsed with PBS $(3 \times 5 \mathrm{~min})$, covered with $1 \% \mathrm{n}$ propyl gallate in $50 \%$ glycerol $/ 50 \%$ PBS, and sealed with a cover slip.

Pulmonary epithelial cell cultures and exposure to agents. Spontaneously derived alveolar type II epithelial cell lines from mouse (C10 line; Reference 16) and rat (RLE-6TN line; Reference 9) were used in these studies. C10 cells were propagated in CMRL-1066 medium (Invitrogen, Carlsbad, CA, USA) supplemented with $10 \%$ fetal bovine serum (FBS), $44 \mathrm{U} / \mathrm{mL}$ penicillin, 44 $\mathrm{ng} / \mathrm{mL}$ streptomycin, and $3.5 \mathrm{mM} \mathrm{L-}$ glutamine. RLE-6TN cells were maintained and passaged in DMEM/F12 medium (Invitrogen) supplemented with 7\% FBS. In general, cell monolayers were grown on glass cover slips to confluency in complete medium (7\%-10\% serum), then transferred into serum-reduced medium $(0.5 \%$ serum or serum-free) $24 \mathrm{~h}$ before exposure to agents. Cells were exposed to the oxidative stress-inducing agents $\mathrm{H}_{2} \mathrm{O}_{2}$ (200 $\mu \mathrm{M}$ ) (Sigma, St. Louis, MO, USA) or crocidolite asbestos fibers $\left(5 \mu \mathrm{g} / \mathrm{cm}^{2}\right)$ [NIEHS reference sample suspended in Hank's Balanced Salt Solution (1 $\mathrm{mg} / \mathrm{mL}$ ) and triturated $10 \times$ through a 22-gauge needle]. Agents were added directly to the culture medium at final concentrations known to induce ERK phosphorylation and/or apoptosis at various time points (6). Sham control cultures received medium without agents and were handled identically.

Immunofluorescence labeling of pERKs in C10 cells. Following treatment, culture dishes were placed on ice, cells were washed two times with ice-cold PBS, fixed in $4 \%$ paraformaldehyde in PBS for $30 \mathrm{~min}$ at room temperature, and permeabilized in pure methanol at $-20^{\circ} \mathrm{C}$ for 10 min. Blocking was achieved with $0.1 \%$ Triton $\mathrm{X}$ 100/2\% nonfat milk/PBS for $30 \mathrm{~min}$ at room temperature, after which cells were washed with $1 \%$ BSA/PBS and incubated with a polyclonal rabbit antipERK 1/2 antibody (1:250 dilution in $1 \%$ BSA/PBS) (New England Biolabs) overnight at $4^{\circ} \mathrm{C}$. Cells were washed two times with $1 \% \mathrm{BSA} / \mathrm{PBS}$ for 20 min, then incubated with a goat antirabbit Alexa 488-conjugated secondary antibody (1:200 dilution in $1 \%$ BSA/PBS) (Molecular Probes) for $1 \mathrm{~h}$ at room temperature. Nuclear DNA was visualized by incubating the cells in a propidium iodide (PI) solution (0.1\% Triton X-100, $20 \mu \mathrm{g} / \mathrm{mL}$ PI, 0.2 $\mathrm{mg} / \mathrm{mL}$ RNase A, $0.5 \mathrm{mM}$ EDTA, $\mathrm{pH}$ 8.0 ) for $25 \mathrm{~min}$ at room temperature. Samples were mounted on glass slides using KPL mounting medium (Kirkegaard and Perry Laboratories, Gaithersburg, MD, USA), sealed, and examined by CSLM.

Immunofluorescence labeling of apoptotic cells. Following treatment, culture dishes were placed on ice, and the cells were washed two times with ice-cold PBS and then fixed in pure methanol at $-20^{\circ} \mathrm{C}$ for $24 \mathrm{~h}$. To induce DNA denaturation in situ, cells were heated to $100^{\circ} \mathrm{C}$ in $\mathrm{PBS}$ containing 5 $\mathrm{mM} \mathrm{MgCl}_{2}$ for $5 \mathrm{~min}$ and then immersed in ice-cold distilled water for 10 min. Cells were then preincubated with $40 \% \mathrm{FBS} / \mathrm{PBS}$ for $15 \mathrm{~min}$ on ice, followed by incubation with a mouse monoclonal antibody to ssDNA (10 $\mu \mathrm{g} / \mathrm{mL}$ in 5\% FBS/PBS) [Apostain (F7-26); Alexis, San Diego, CA, USA] for $30 \mathrm{~min}$ at room temperature. Following washes with PBS $(2 \times 15 \mathrm{~min})$ the cells were incubated with an Oregon Green ${ }^{\circledR}$ 488-conjugated goat anti- 
mouse secondary antibody $(5 \mu \mathrm{g} / \mathrm{mL}$ in $5 \%$ FBS/PBS) (Molecular Probes) for $30 \mathrm{~min}$ at room temperature. Nuclear DNA was visualized by incubating the cells with PI solution as described above. Samples were mounted on glass slides using 90\% glycerol in PBS, sealed, and stored at $-20^{\circ} \mathrm{C}$ for up to 24 $\mathrm{h}$ before analysis by LSC.

Transient transfection. RLE-6TN cells were transfected with a dominant negative mutant form of ERK, MEK1 (dnMEK1), constructed in the pVL1392 plasmid carrying green fluorescent protein (GFP) as a marker of transfection (pVL1392-dnMEK1). Cells were electroporated using a Gene Pulser ${ }^{\mathrm{TM}}$ (BioRad Laboratories, Hercules, CA, USA) and the manufacturer's recommended protocols. Sham control groups were transfected with empty vector, that is, plasmid carrying only the GFP marker (pVL1392). Following transfection, cells were plated and allowed to recover overnight in 7\% FBS-containing culture medium before the addition of $\mathrm{H}_{2} \mathrm{O}_{2}(200 \mu \mathrm{M})$ for $24 \mathrm{~h}$. Following treatment, cells were fixed in $75 \%$ ethanol for $30 \mathrm{~min}$ at room temperature, and nuclear DNA was stained with PI as described above. Samples were mounted on glass slides in $90 \%$ glycerol in PBS, sealed, and stored at $-20^{\circ} \mathrm{C}$ for up to $24 \mathrm{~h}$ before analysis by LSC.

\section{Preparation of Lung Sections for LCM}

Mouse lung bronchiolar epithelial cells were specifically retrieved from cryostat sections of frozen mouse lung. Five to $8 \mu \mathrm{m}$ thick sections were cut at $-23^{\circ} \mathrm{C}$ with stainless-steel blades mounted in a MICROM Microtome Cryostat and picked up onto untreated or Fisherbrand ${ }^{\circledR}$ Superfrost/Plus-treated slides (Fisher Scientific, Pittsburgh, PA, USA). The sections were fixed for 1 min in $70 \%$ ethanol, followed by staining with hematoxylin and eosin. To ensure maximal dehydration of the sections required for effective cell capture, the sections were stored in a dessicator until the time of laser capture. Laser capture was performed with an Arcturus PixCell II ${ }^{\circledR}$ LCM system (Arcturus Engineering, Mountain View, CA, USA) according to the manufacturer's protocol. In LCM, a plastic disk coated with a film containing a thermally sensitive component (CapSure ${ }^{\mathrm{TM}}$ LCM Transfer Film; Arcturus Engineering) contacts non-cover-slipped, paraffin-embedded or cryostat sections (see Results and Discussion section for details).

Hematoxylin and eosin (H\&E) staining. H\&E staining of sections was done according to the H\&E Staining Protocol for LCM adapted from the National Institutes of Health, which is available online at www.arctur.com/ technology/h_2.html. Briefly, slides were fixed in $70 \%$ ethanol for $30 \mathrm{~s}$, followed by a 30-s distilled water rinse. Sections were stained in Mayer's hematoxylin for $1 \mathrm{~min}$, followed by a distilled water rinse. For differentiation, sections were dipped in Blueing Reagent $(0.25 \%$ ammonia in distilled water) for $30 \mathrm{~s}$. Sections were then washed in $70 \%$ ethanol for $1 \mathrm{~min}$, followed by a $95 \%$ ethanol wash for 1 min. Sections were further differentiat- ed by staining in eosin for $15 \mathrm{~s}$ and subsequently washed two times in $95 \%$ ethanol for $1 \mathrm{~min}$, followed by a $1-\mathrm{min}$ $100 \%$ ethanol wash. Sections were then dehydrated by two 10-min xylene washes. Dehydrated sections were air dried for $10 \mathrm{~min}$ and then stored at room temperature in a dessicator.

RNA isolation from CapSure LCM Transfer Film caps. The RNA extraction protocol is a modification of the Stratagene Microisolation Protocol (Stratagene, La Jolla, CA, USA). CapSure LCM Transfer Film plastic caps containing captured lung distal bronchiolar epithelial cells were placed into 0.5-mL microcentrifuge tubes containing $200 \mu \mathrm{L}$ RNA denaturing buffer [stock solution: $250 \mathrm{~g}$ guanidine, 293 $\mathrm{mL}$ sterile distilled water, $17.6 \mathrm{~mL} 0.75$ M sodium citrate $(\mathrm{pH} 7.0), 26.4 \mathrm{~mL}$ $10 \%$ sarkosyl (N-lauroylsarcosine), $720 \mu \mathrm{L} \quad \beta$-mercaptoethanol]. Tubes were inverted over the course of 2 min

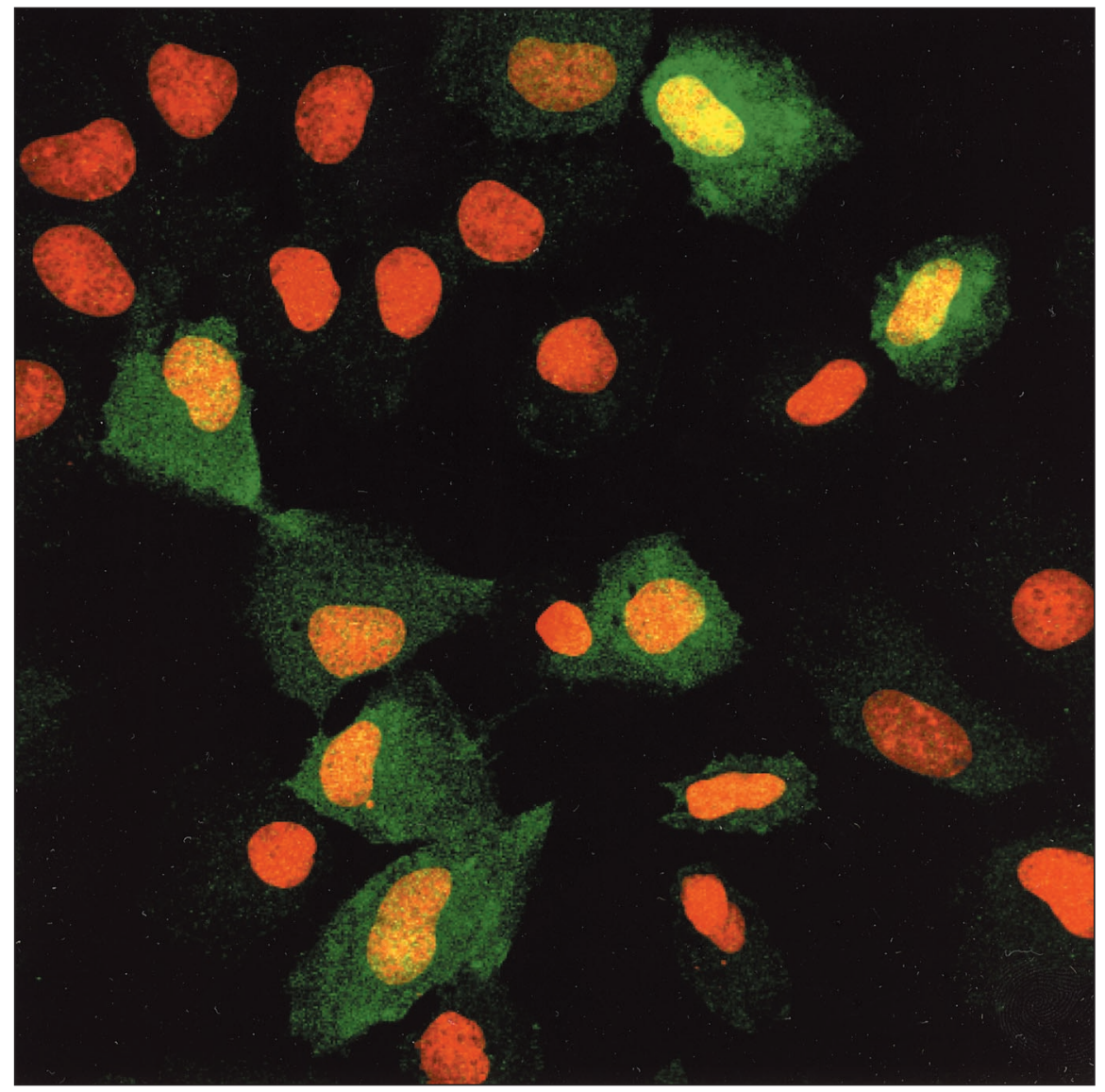

Figure 1. Localization of pERK in mouse C10 lung cells by CSLM. Following treatment of cells with crocidolite asbestos $\left(5 \mu \mathrm{g} / \mathrm{cm}^{2}\right)$ for $2 \mathrm{~h}$, a dramatic increase in cytoplasmic and nuclear pERK is observed. Cells were doubly stained with PI (red signal) and an anti-pERK antibody followed by an Alexa 488-conjugated secondary antibody (green signal). Original microscope magnification $1000 \times$. 
to dissolve the cells into the buffer. Caps were removed, and the following reagents were added to the RNA buffer containing cells: $20 \mu \mathrm{L}(0.1 \times$ volume $)$ of $2 \mathrm{M}$ sodium acetate ( $\mathrm{pH} 4.0), 220 \mu \mathrm{L}$ (1× volume) water-saturated phenol, and $60 \mu \mathrm{L}(0.3 \times$ volume $)$ chloroformisoamyl alcohol. Tubes were vortex mixed and placed on ice for $15 \mathrm{~min}$. Aqueous and organic layers were separated in a desktop microcentrifuge at $20000 \times g$ for $30 \mathrm{~min}$ at $4^{\circ} \mathrm{C}$. Following centrifugation, the upper aqueous layer was transferred to a new tube, and $1 \mu \mathrm{L}$ linear polyacrylamide was added to the aqueous solution to act as a carrier and to help visualize the pellet in subsequent steps. To the aqueous solution, $200 \mu \mathrm{L}$ cold isopropanol were added, and RNA was precipitated at $-20^{\circ} \mathrm{C}$ for 1 h. After precipitation, samples were centrifuged at $20000 \times g$ for $30 \mathrm{~min}$ at $4^{\circ} \mathrm{C}$, and all solution was removed. The RNA pellet was washed with $200 \mu \mathrm{L}$ cold $70 \%$ ethanol by centrifugation at $20000 \times g$ for $5 \mathrm{~min}$. All ethanol was removed, and pellets were air dried for 5 min, dissolved in $40 \mu \mathrm{L}$ nuclease-free water, and stored at $-20^{\circ} \mathrm{C}$.

cDNA synthesis. Before cDNA synthesis, all RNA samples were DNase treated using reagents from Promega (Madison, WI, USA). The protocol used was a modification of the recommendations of the manufacturer and is based on $10 \mu \mathrm{L}$ final volume. For each RNA sample, two tubes were used, one of which was subsequently used as a "No RT" control in cDNA synthesis. In each tube, $1 \mu \mathrm{g}$ RNA was mixed with 1 $\mu \mathrm{L}$ RQ1 DNase $10 \times$ reaction buffer, 1 U RQ1 DNase (1 U/ $\mu \mathrm{L})$, and nucleasefree water up to $10 \mu \mathrm{L}$ final volume. Reactions were incubated at $37^{\circ} \mathrm{C}$ for 30 min, after which $1 \mu \mathrm{L}$ RQ1 DNase Stop Solution (25 mM EGTA) was added and the reactions were heated to $65^{\circ} \mathrm{C}$ for $10 \mathrm{~min}$. cDNA synthesis was conducted in the same tubes as the DNase reactions, and reagents were provided in the Promega Reverse Transcription Kit. For each sample, the following reagents were added for a final volume of $20 \mu \mathrm{L}: 4 \mu \mathrm{L} 25 \mathrm{mM} \mathrm{MgCl}_{2}$ (5 mM final concentration), $2 \mu \mathrm{L}$ RT $10 \times$ Reaction Buffer $(1 \times$ final concentration), $2 \mu \mathrm{L} 10 \mathrm{mM}$ dNTP mixture (1 $\mathrm{mM}$ final concentration), $0.5 \mu \mathrm{L}$ RNasin (1 U/ $\mu \mathrm{L}$ final concentration), and $1 \mu \mathrm{L}$ Random Primers $(0.5 \mu \mathrm{g})$. Tubes labeled "No RT" were brought up to $20 \mu \mathrm{L}$ final volume with nucleasefree water. To the remaining reaction tubes, $1 \mu \mathrm{L}$ AMV reverse transcriptase

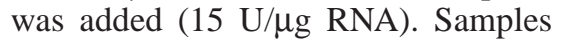
were incubated at room temperature for $10 \mathrm{~min}$, followed by heating at $42^{\circ} \mathrm{C}$ for $1 \mathrm{~h}$. Reactions were stopped by heating at $95^{\circ} \mathrm{C}$ for $5 \mathrm{~min}$, followed by cooling on ice for $5 \mathrm{~min}$. Samples were stored at $-20^{\circ} \mathrm{C}$ until further use.

Quantitative real-time PCR. cDNA generated from LCM as de- scribed above was analyzed for the gene expression of c-jun using quantitative PCR (TaqMan ${ }^{\circledR}$; Applied Biosystems, Foster City, CA, USA). Standard TaqMan reactions and protocols were used. Specifically, reactions contained 200 and $900 \mathrm{nM}$ of c-jun probe and primers, respectively. As a control for positive c-jun expression, cDNA was synthesized from RNA isolated from cultured $\mathrm{C} 10$ cells exposed to 12-Otetradecanoyl-phorbol acetate (TPA) for $2 \mathrm{~h}$ (28). This cDNA was also used to generate a standard curve for C10

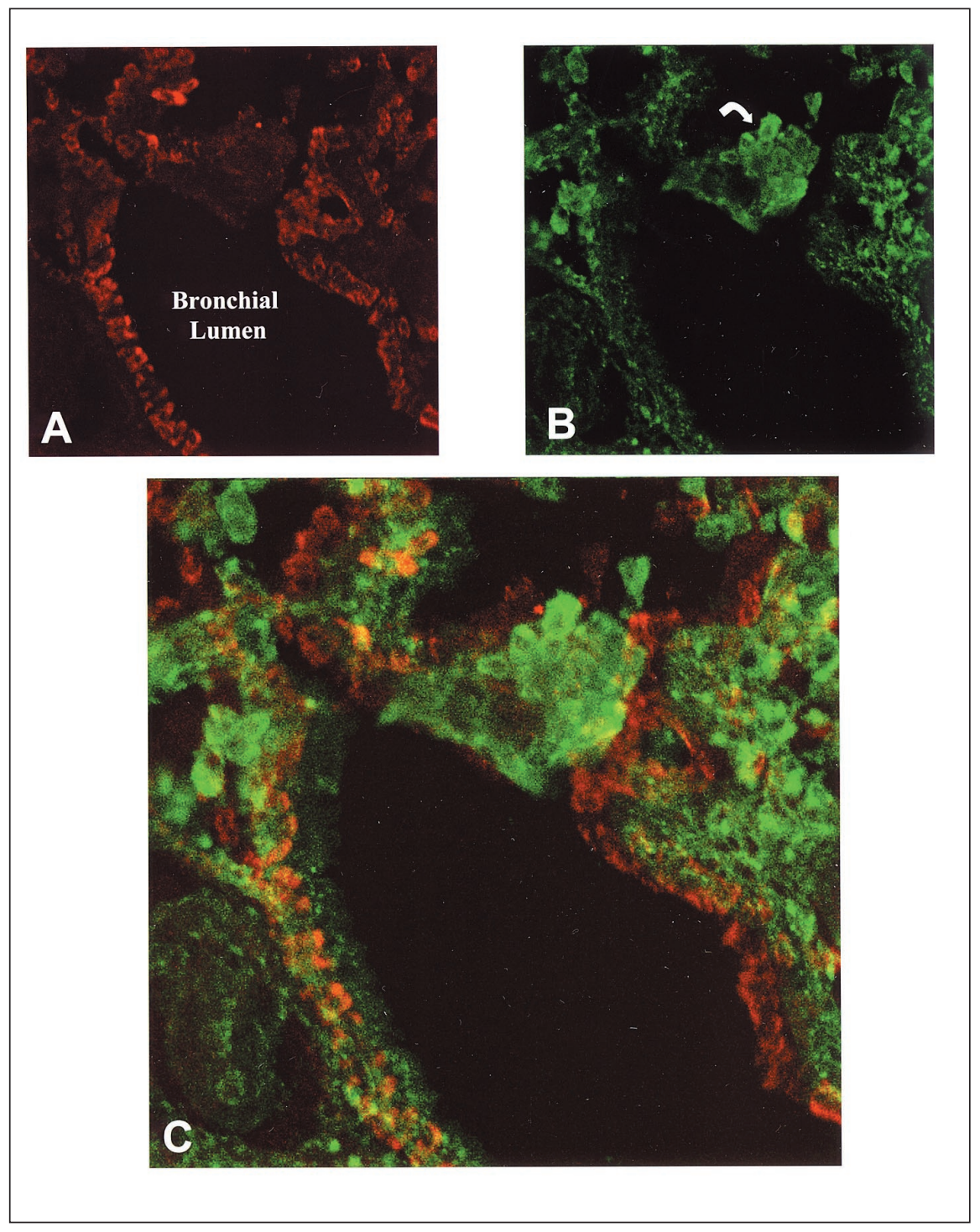

Figure 2. Localization of pERK in cryostat sections from 30-day crocidolite-exposed mouse lungs by CSLM. (A) pERK antibody followed by Alexa 568-conjugated fluorophore. Note staining of bronchial epithelial cell cytoplasm. (B) Mac3 anti-macrophage antibody followed by Alexa 488-conjugated flourophore. Positively stained macrophages are indicated by arrows. (C) Electronic merge of images A and B. Note the lack of co-localization of the two antibodies in the bronchial epithelium. Images captured as 8-bit, $512 \times 512$-pixel format. Original microscope magnifications $400 \times$. 
expression of c-jun using serial dilutions of C10 cDNA as template. Both LCM cDNA and C10 cDNA were also analyzed for expression of the constitutive $18 \mathrm{~S}$ gene as an internal control.

\section{RESULTS AND DISCUSSION}

We have used several state-of-theart microscopy-based imaging systems incorporating lasers for investigating MAPK cell signaling pathways and AP-1 family members in oxidant-induced injury. In the following sections, we will describe results achieved with mouse lung and cultured lung epithelial cells using these various imaging approaches. Our goal is to demonstrate the utility of combining several diverse microscopy-based imaging approaches in the investigation of mechanisms of environmental lung disease $(3,17)$.

\section{CSLM}

To determine the cellular localization of pERK in cells and changes in patterns of localization after exposure to asbestos, a fiber inducing oxidative stress $(18,23)$, cells and lung tissue sections were imaged with a Bio- $\operatorname{Rad}^{\circledR} \mathrm{MRC}$ 1024ES confocal scanning laser microscopy system (Bio-Rad Laboratories). This system consists of a Bio-Rad scan head mounted on an Olympus ${ }^{\circledR}$ BX-50 upright light microscope (Olympus America, Melville, NY, USA). Fluorescence excitation is achieved with a mixed gas krypton/argon laser, delivering wavelengths of 488, 568, and 647 $\mathrm{nm}$ through a fiber optic couple to the scan head. A three-color transmitted light detector is also fitted onto the microscope, allowing for digital capture of non-confocal transmitted and phasecontrast images. This feature is particularly useful for combining images of fluorescence staining in cells, with a phase-contrast image showing cell structure. The main feature of confocal microscopy that is of interest to us in the present studies is its ability to reject outof-focus fluorescence signal (20). By matching numerical aperture of an objective lens with optimal confocal aperture diameter, we can achieve both high contrast and resolution for imaging of signaling proteins in cultured cells and tissue sections. As shown in Figure 1, following exposure of $\mathrm{C} 10$ cells to crocidolite asbestos for $2 \mathrm{~h}$, a dramatic increase in cytoplasmic and nuclear pERK expression is observed. Moreover, after time periods from 8 to $24 \mathrm{~h}$ following the addition of fibers, nuclear translocation of pERK is maintained (6). In contrast, pERK was undetectable in confluent, untreated cells (not shown).

Confocal microscopy is particularly well suited for the examination of thicksectioned tissues, where fluorescence signal generated from out-of-focus image planes deteriorates image quality by reducing contrast and resolution. We have used CSLM to examine the localization of pERK in 7-10 $\mu \mathrm{m}$ thick cryostat sections from mouse lungs after inhalation of asbestos. In contrast to the absence of staining in unexposed control mouse lungs, we found staining for
pERK to be localized predominantly to the cytoplasm of bronchial epithelial cells (Figure 2A). Additionally, some cells in the alveolar region were also observed to stain positively for pERK. We believe that these cells are alveolar type epithelial II cells that proliferate in response to asbestos-induced injury (24). Dual labeling studies are in progress to confirm this supposition. However, since these positively staining cells could also potentially be alveolar macrophages, we have doubly stained mouse lung sections with the pERK antibody and with Mac3, a macrophagespecific antibody. We found that cells staining positively with the Mac3 antibody (Figure 2B) were not labeled for pERK (Figure 2C). These results support our premise that pERK will be found in alveolar type II epithelial cells and not in alveolar macrophages.

We have used CSLM extensively in
A

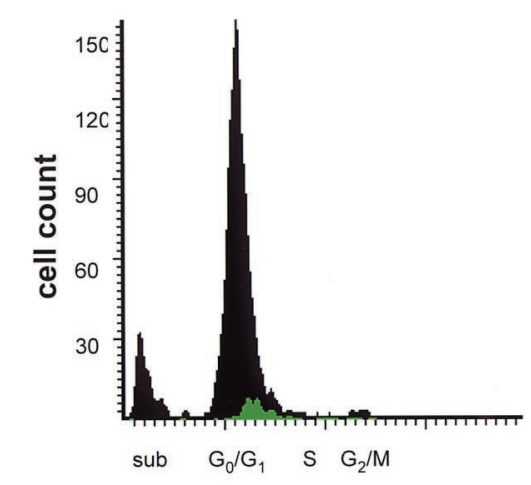

C

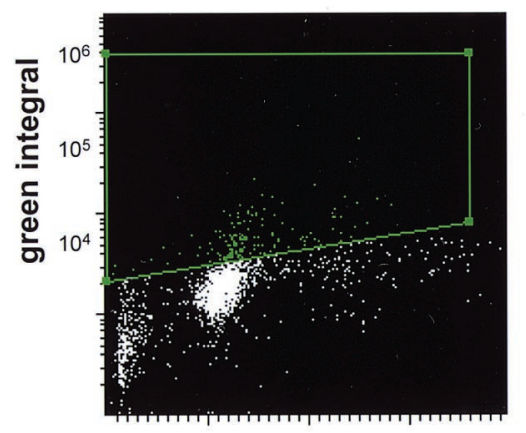

B

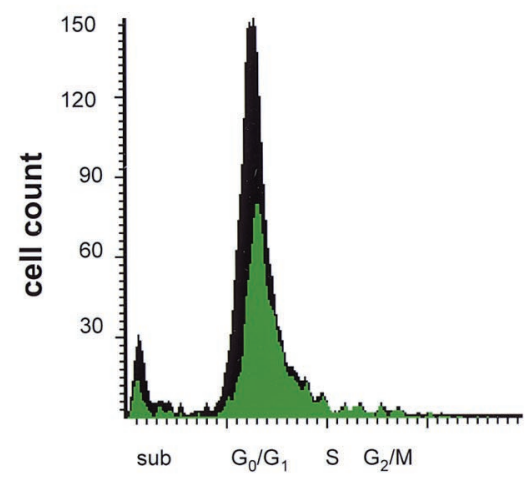

D

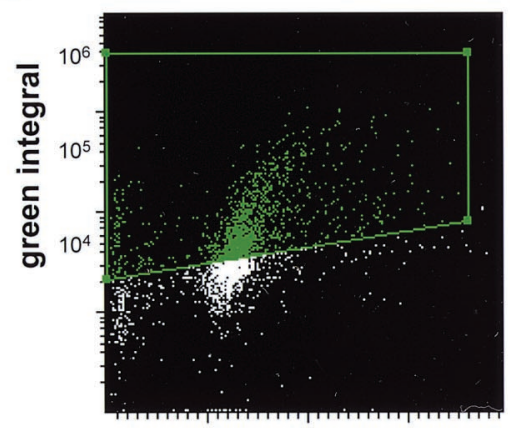

Figure 3. LSC analysis of cell cycle distribution and pERK expression in C10 cells. Cells were stained with PI and an antibody against pERK, followed by an Alexa 488-conjugated secondary antibody. DNA histograms show cell cycle analysis for sham control cells (A) and cells exposed to crocidolite asbestos $\left(5 \mu \mathrm{g} / \mathrm{cm}^{2}\right)$ for $4 \mathrm{~h}$ (B). Scatter plots of pERK expression for these cells are shown in panels $\mathrm{C}$ and $\mathrm{D}$ (sham control and asbestos treated, respectively). The green portion of the DNA histograms represents the pERK positively stained cells taken from the green gated regions in the scatter plots. 
the past in our investigations of the effects of environmental agents on lung cells and tissues. These studies included assessing the effects of oxidant injury on cell proliferation, apoptosis, and DNA repair $(3,6,7,11,19,22,24,28)$. We will continue to use CSLM as a powerful tool for the examination of protein expression and cellular outcome in response to environmental agents.

\section{LSC}

LSC was performed using the LSC ${ }^{\circledR}$ Laser Scanning Cytometer from CompuCyte (Cambridge, MA, USA) with WinCyte 3.3 data analysis software. This instrument is essentially a hybrid flow cytometer/microscopebased imaging system $(8,14,15)$. Fluorescently labeled cell preparations (or

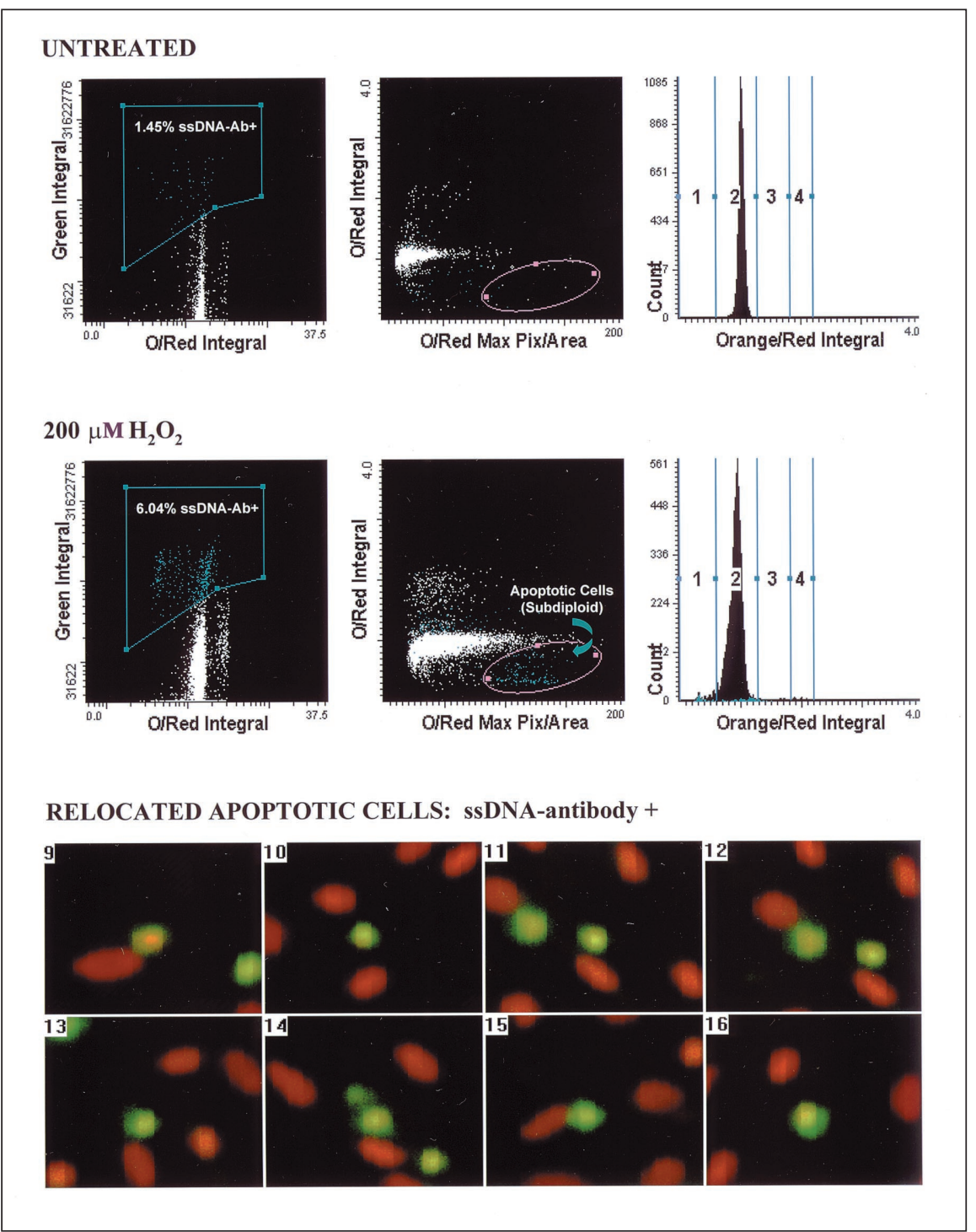

Figure 4. Detection of apoptotic lung epithelial cells using ssDNA-antibody (Apostain) and LSC. (Upper panel) Scattergrams showing percentage of Apostain-positive cells (green integral versus orange/red integral), the apoptotic fraction (orange/red integral versus orange/red maximum pixel), and a DNA histogram for untreated C10 cells. (Middle panel) Scattergrams showing percentage of Apostainpositive cells (green integral versus orange/red integral), the apoptotic fraction (orange/red integral versus orange/red maximum pixel), and a DNA histogram for C10 cells treated with $200 \mu \mathrm{M} \mathrm{H}_{2} \mathrm{O}_{2}$ for $24 \mathrm{~h}$. Note the increased number of Apostain-positive cells and the enhanced subdiploid DNA fraction in cells treated with $\mathrm{H}_{2} \mathrm{O}_{2}$ as compared with the sham controls. (Bottom panel) Cell relocation feature of LSC demonstrated for eight cells. Cells within the subdiploid fraction (elliptical region highlighted on scattergram in middle panel) were relocated and visually confirmed as apoptotic by morphological appearance and positive staining with the ssDNA antibody. 
tissue sections) are placed onto a glass slide and secured onto a motorized microscope stage mounted on an Olympus BX 50 light microscope. The specimen is scanned by an argon or helium/neon laser, and the resulting fluorescence emission is delivered to a photomultiplier tube after passing through appropriate filter blocks. The resulting data are displayed in the form of scattergrams and histograms, similar to flow cytometry. Detailed descriptions of LSC methodology have been published previously $(8,14,15)$. To evaluate pulmonary epithelial cell monolayers using LSC, the scan area was defined to include at least 5000 cells for analysis. Alternatively, a set scan area was utilized to assess and compare cell density between samples. Slides were scanned under a $20 \times$ objective lens using the $488 \mathrm{~nm}$ wavelength argon laser with red and green fluorescence detectors. The primary contouring parameter, used to detect and quantify cells, was set on red fluorescence of PI-stained nuclei. Detector gain voltages were set so that a maximum of $75 \%$ saturation was achieved for the brightest maximum pixel event scanned. Threshold contouring was done essentially as described by Darzynkiewicz and co-workers (8). Using the scan data display, the threshold contour was placed within the nucleus at a distance one-third from the nuclear border, and the integration contour, used to compute nuclear integrated fluorescence, was located four pixels outside the threshold contour (8). Peripheral contours were set to measure integrated fluorescence of the cytoplasm by specifying an inner and outer boundary that included the majority of the cytoplasmic rim outside the measured nuclear area (8). Background was measured outside the cell and automatically subtracted from the nuclear and cytoplasmic integrated fluorescence values. A variety of scatter plots and histograms, displayed on the LSC computer screen, were utilized in these studies, depending on the specific application. Plotting and scales were done automatically by the LSC instrument.

Data derived from the LSC are similar in format to those obtained by flow cytometry. For example, Figure 3 shows representative displays of LSC mea- surements of changes in cell cycle distribution (DNA content) and pERK expression in C10 pulmonary epithelial whether asbestos-induced expression of pERK was cell cycle-related. pERK was detected immunocytochemically using an Alexa 488-conjugated secondary antibody, and nuclear DNA was visualized with PI. At least 5000 cells were analyzed for each sample. DNA histograms show the subdiploid, $\mathrm{G}_{0} / \mathrm{G}_{1}$, $\mathrm{S}$ phase, and $\mathrm{G}_{2} / \mathrm{M}$ fractions in sham control cells (Figure 3A) and in cells exposed to asbestos $\left(5 \mu \mathrm{g} / \mathrm{cm}^{2}\right)$ for $4 \mathrm{~h}$ (Figure 3B). Beneath each histogram is the corresponding scatter plot showing pERK expression in relation to the cell cells, where LSC was used to determine

cycle in sham control cells (Figure 3C) and in asbestos-exposed cells (Figure 3D). The gated region in the scatter plots indicates the population of pERKpositive cells, also represented by the green shading in the DNA histograms (Figure 3, A and B). Asbestos exposure induced a 5-fold increase in the percentage of pERK-positive cells (12\% versus $61 \%$ ). At all time points, over $90 \%$ of sham control cells were in $\mathrm{G}_{0} / \mathrm{G}_{1}$, with only $1 \%$ in $S$ phase and $5 \%$ in $\mathrm{G}_{2} / \mathrm{M}$. Similar cell cycle distributions were observed in asbestos-exposed cells; however, the $S$ phase and $\mathrm{G}_{2} / \mathrm{M}$ fractions appeared to expand with longer exposure times to asbestos (6). Thus, LSC data support the premise that asbestos-in-

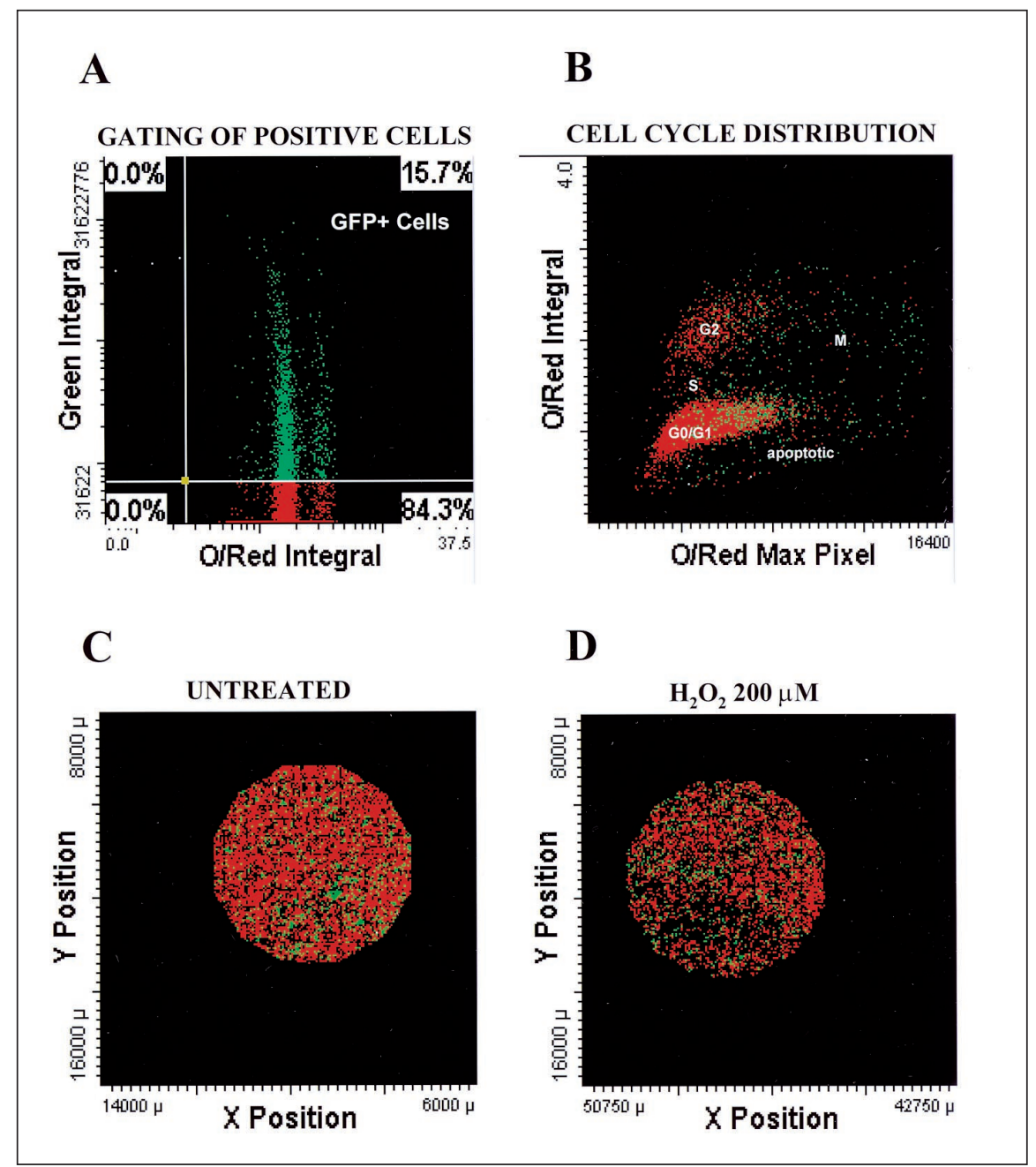

Figure 5. Analysis of transient transfection experiment of lung epithelial cells using LSC. (A) Scattergram representing orange/red integral versus green integral shows that $15.7 \%$ of the cells were transfected. (B) Scattergram of orange/red maximum pixel versus orange/red integral illustrates cell cycle distribution of total cell population on the cover slip. There is a mixed distribution of transfected and non-transfected cells throughout the cell cycle. (C) X,Y coordinate plots reveal a lower cell density in the $\mathrm{H}_{2} \mathrm{O}_{2}$-treated cells (D) versus sham-treated cells (C). The transfection marker is GFP, and the DNA counterstain is PI. 


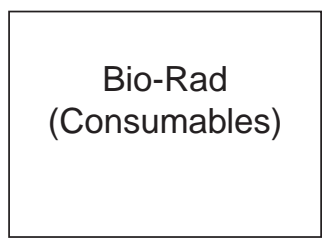

Circle Reader Service No. 217 
duced expression of pERK occurs preferentially in cells in $S$ and $G_{2} / M$ phases of the cell cycle. This observation may be relevant to cell cycle alterations induced by asbestos, including increases in cell proliferation associated with the development of lung cancers and fibrosis or repair $(17,22)$.

LSC has been characterized as well suited for the evaluation of apoptosis (2). Figure 4 depicts representative LSC display windows showing analysis of apoptosis in C10 cells exposed to $\mathrm{H}_{2} \mathrm{O}_{2}(200 \mu \mathrm{M})$ for $24 \mathrm{~h}$, then stained with a ssDNA primary antibody (Apostain), an Oregon Green 488-conjugated secondary antibody, and PI. The gate designating cells staining positive for the ssDNA antibody was set using samples stained with PI only or with Apostain/Oregon Green 488 only and was confirmed visually using the scan data display. In scattergrams plotting the orange/red integral (PI staining of nuclear DNA) against the green integral, sham control cells demonstrated only $1.45 \%$ Apostain positivity (Figure 4, upper panel), versus $6.04 \%$ in the $\mathrm{H}_{2} \mathrm{O}_{2}$-exposed sample (Figure 4, middle panel). Localization of the subdiploid (apoptotic) fraction was facilitated in scattergrams plotting the orange/red maximum pixel per area against the orange/red integral and confirmed that the majority of Apostain-positive cells in the $\mathrm{H}_{2} \mathrm{O}_{2}$-treated sample were in the subdiploid (apoptotic) fraction (Figure 4 , middle panel). DNA histograms also demonstrated an increase in the subdiploid (apoptotic) fraction in the treated sample (Figure 4, middle panel) versus the sham control sample (Figure 4, upper panel). The gallery of cells (Figure 4, bottom panel) demonstrates visual confirmation of apoptotic cytomorphology using the instrument's cell relocation and image capture capabilities. Cells that are positive for the ssDNA antibody (green) show decreased nuclear size and DNA hypercondensation (yellow) in contrast to the nuclei of non-apoptotic cells (red).

Previous studies in our laboratory have indicated that asbestos-induced activation of the ERK pathway is linked upstream to EGF receptor phosphorylation and downstream to c-fos induction and apoptosis $(19,29,30)$. We developed a transient transfection protocol, in which a dominant negative mutant form of MEK1 was introduced to block activation of ERKs. We hypothesized that activation of ERKs was causally related to apoptosis in pulmonary epithelial cells subjected to oxidative stress. RLE-6TN cells were transfected with pVL1392-dnMEK1 or pVL1392 (empty vector) and exposed to $\mathrm{H}_{2} \mathrm{O}_{2}$ $(200 \mu \mathrm{M})$ for $24 \mathrm{~h}$ to induce apoptosis and then analyzed by LSC.

Figure 5 depicts representative display windows exemplifying the utility of LSC in analysis of our transfection studies. The scattergram of the orange/red integral (PI staining of nuclear DNA) plotted against the green integral (Figure 5A) demonstrates 15.7\% transfection in a representative sample (versus less than $0.5 \%$ in sham controls; not shown). The gate was set using samples stained with PI only or with GFP only and was confirmed visually using the instrument's scan data display. Cell cycle distribution of the total cell population is demonstrated in the scatter plot of orange/red maximum pixel versus orange/red integral (Figure 5B). There is mixed distribution of non-transfected (red) and transfected cells (green) throughout the various phases of the cell cycle. The instrument's $\mathrm{X}$ and $\mathrm{Y}$ coordinates plot the exact location of cells within a scan area, demonstrating lower cell density in a sample exposed to $\mathrm{H}_{2} \mathrm{O}_{2}$ (Figure 5D) versus a sham control sample (Figure 5C). $\mathrm{H}_{2} \mathrm{O}_{2}$ exposure appeared to affect non-transfected (red) as well as transfected (green) cells. Selective gating enabled separate analysis of the relatively small subset of transfected cells in each sample, allowing evaluation of the effect of $\mathrm{H}_{2} \mathrm{O}_{2}$ exposure in this population of interest. Figure 6 shows DNA distribution histograms for samples representing the four transfection groups: pVL1392 (empty vector), untreated and treated; pVL1392-dnMEK1, untreated and treated. Cells transfected with the empty vector show the typical endpoint of $\mathrm{H}_{2} \mathrm{O}_{2}$ exposure [i.e., an increase in the subdiploid (apoptotic) fraction] (Figure 6B) versus the untreated sample (Figure 6A). In contrast, cells transfected with the dominant negative mutant

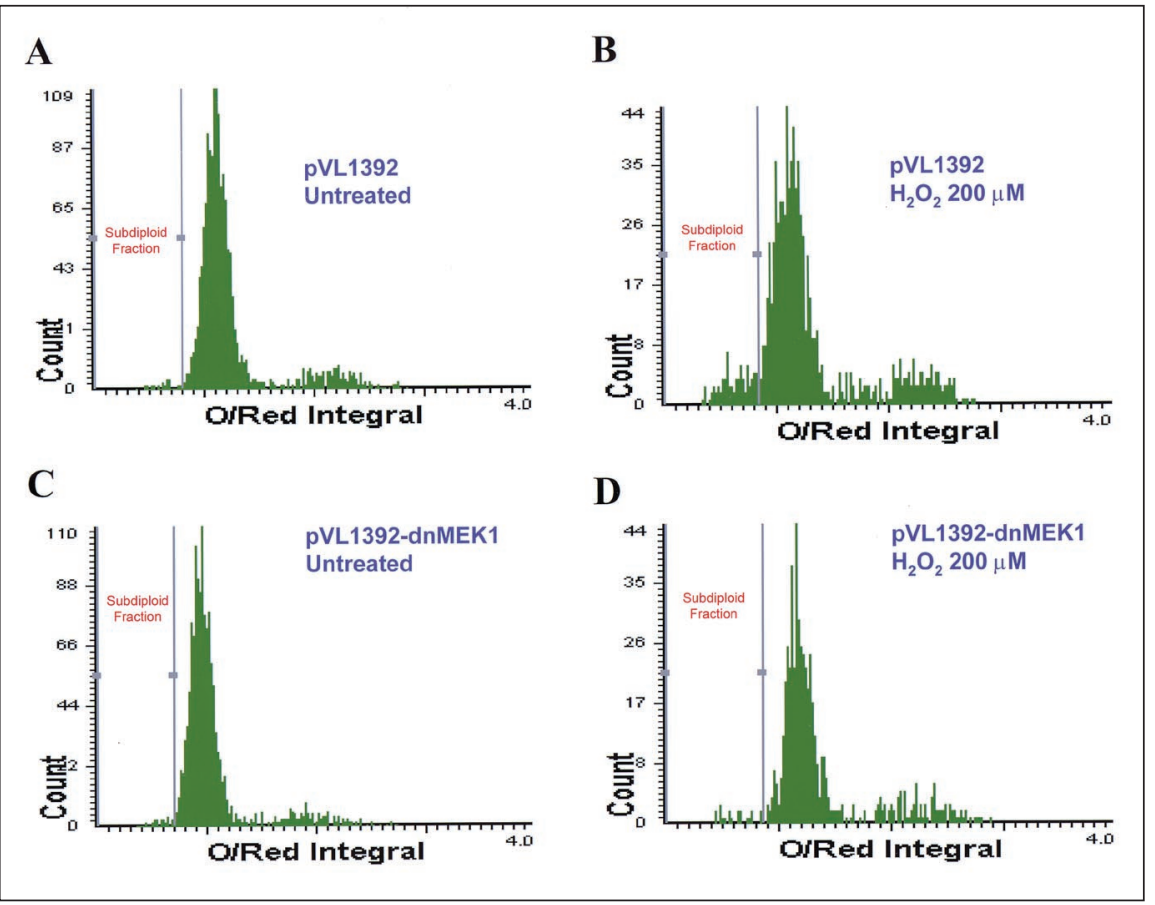

Figure 6. Detection of a subdiploid (apoptotic) fraction in transfected (GFP+) lung epithelial cells using LSC. DNA histograms from untreated cells transfected with empty vector (A), empty vector transfection from cells treated with $\mathrm{H}_{2} \mathrm{O}_{2}$ (B), untreated cells transfected with dominant negative mutant form of MEK1 (C), and cells transfected with dominant negative mutant form of MEK1 and treated with $\mathrm{H}_{2} \mathrm{O}_{2}$ (D). Note that, in cells transfected with an empty vector and treated with $\mathrm{H}_{2} \mathrm{O}_{2}$, an increase in the subdiploid DNA fraction (apoptotic) is detected (" $\mathrm{B}$ " versus " $\mathrm{A}$ "). In contrast, transfection with dominant negative form of MEK1 protects cells from undergoing apoptosis in response to $\mathrm{H}_{2} \mathrm{O}_{2}$ treatment ("B" versus "D"). 
form of MEK1 exhibit an attenuated $\mathrm{H}_{2} \mathrm{O}_{2}$ effect, with comparatively fewer cells in the subdiploid (apoptotic) fraction (Figure 6D) versus the untreated sample (Figure 6C). The combined data from two separate transfection experiments are presented in Figure 7, which quantifies the percentage of transfected cells in the subdiploid (apoptotic) fraction for each group and shows ablation of the $\mathrm{H}_{2} \mathrm{O}_{2}$ effect in cells transfected with dnMEK1. These data support the premise that ERK activation is causally linked to oxidative stress-induced apoptosis in pulmonary epithelial cells.

\section{LCM}

LCM is a relatively new innovation for the precise removal of specific cells from a section of complex tissue for subsequent molecular analysis. This instrument was developed at the National Institutes of Health (10) and is now manufactured by Arcturus Engineering as the PixCell II. In this system, a noncover-slipped cryostat section or paraffin-embedded section is contacted by a $6 \mathrm{~mm}$ diameter plastic flat cap coated with an ethylene vinyl acetate transfer film incorporating a near-infrared absorbing dye $(4,10,25,26)$. Cells of interest are located in the microscope field, and an infrared laser pulse of approximately $812 \mathrm{~nm}$ wavelength is directed over the cells, transiently melting the transfer film around the cells. The film immediately begins to cool, forming a strong bond with the cells. When the cap is lifted off of the section, the targeted cells are retrieved with the cap,

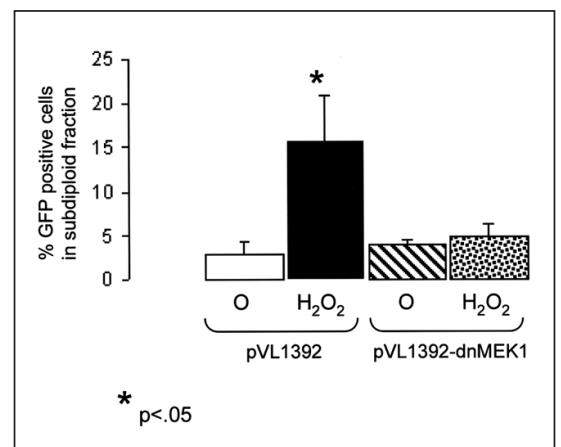

Figure 7. Analysis of transfection experiments using LSC. Data were combined from two transfection experiments and demonstrate the protective effect of dominant negative MEK1 transfection against $\mathrm{H}_{2} \mathrm{O}_{2}$-induced apoptosis. which is then placed into a reagent tube containing appropriate extraction buffer. The predicted local temperature rise from the laser pulse appears insufficient to damage DNA, mRNA, or proteins (12), making the LCM a versatile tool for both genomics and proteomics.

We are interested in using LCM and quantitative real-time PCR (TaqMan) to determine whether expression of c-fos and c-jun protooncogenes, the genes activated by MAPK signaling, is increased in distal bronchiolar and alveolar type II epithelial cells of mice exposed by inhalation to asbestos. Protocols have been established for tissue preparatory methods required for the optimal isolation of mRNA from LCM specimens (13). We have essentially followed the recommendation of Goldsworthy and

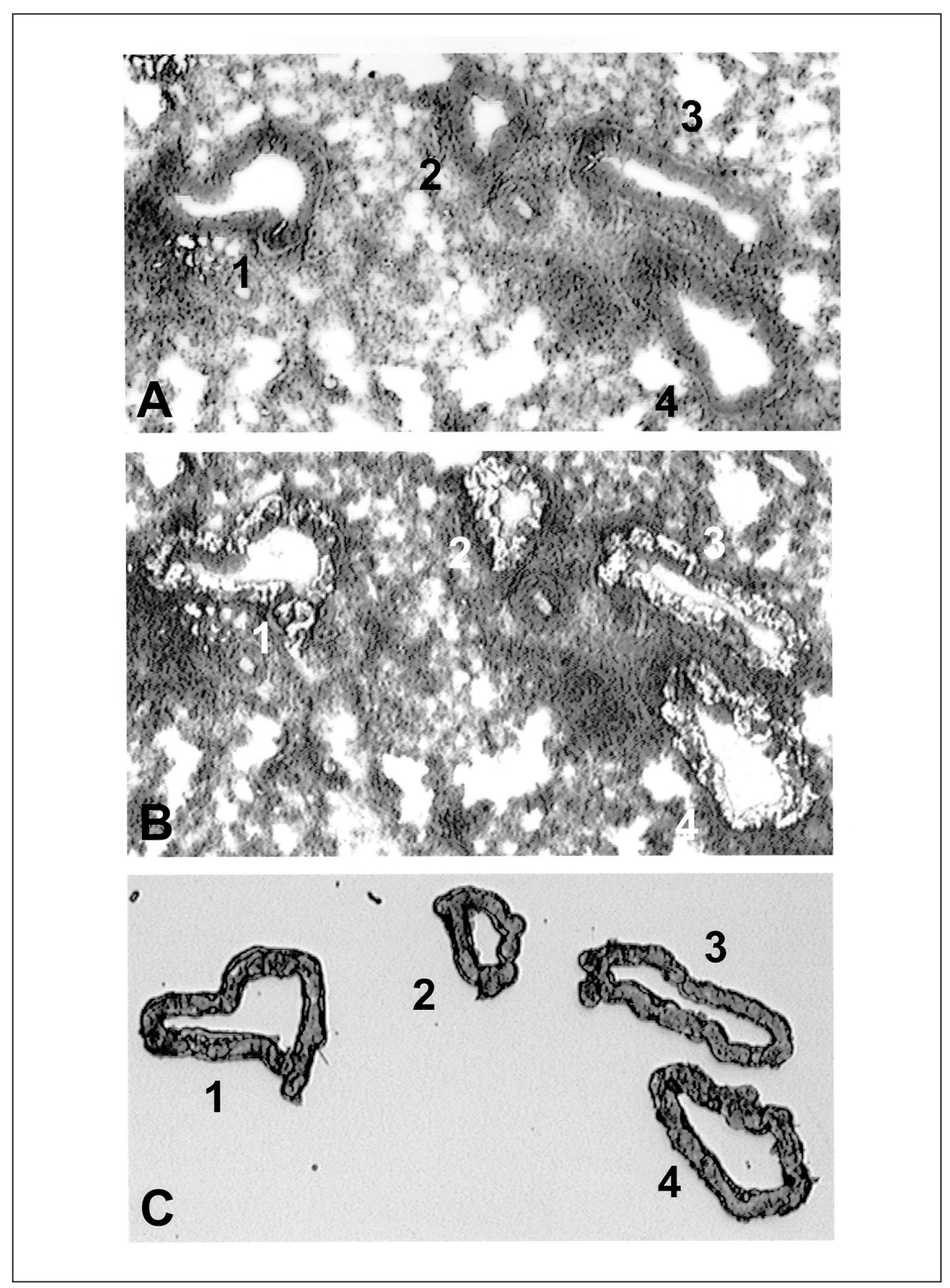

Figure 8. LCM of mouse lung bronchial epithelial cells. (A) A cryostat section from mouse lung stained with H\&E before LCM. The numbers indicate four bronchioles. (B) The same section immediately following LCM removal of bronchiolar epithelial cells. Note the white portions of the bronchiolar epithelium, which represent the holes remaining in the tissue following cell capture. (C) An image of the CapSure LCM Transfer Film cap used in this experiment, showing the captured bronchiolar epithelial cells. Note the matching shape of the cells on the cap with those present in the intact tissue (A). Original microscope magnifications $200 \times$. 
Table 1. $C_{t}$ Values for 18S RNA and c-jun Generated by the Standard Curve Method

\begin{tabular}{|lll|}
\hline & $\mathbf{C}_{\mathbf{t}}$ Value & $\mathbf{C}_{\mathbf{t}}$ Value \\
\hline cDNA & $18 \mathrm{~S}$ & $\mathrm{c}$-jun \\
Standard 1a & 11.32 & 25.6 \\
Standard 2 & 13.2 & 27.46 \\
Standard 3 & 14 & 28.37 \\
Standard 4 & 17.36 & 31.8 \\
Standard 5 & 21.1 & 35.6 \\
Lung & 19.3 & 33.5 \\
Epithelium & & \\
aStandard values represent serially \\
diluted values from 18S RNA and \\
c-jun generated from C10 cells. \\
\hline
\end{tabular}

co-workers (13), whereby O.C.T.-protected lung tissue was frozen unfixed in liquid nitrogen cooled isopentane. Following preparation of cryostat sections, the sections were very briefly fixed in $70 \%$ ethanol, lightly contrasted with $\mathrm{H} \& \mathrm{E}$, and air dried and dessicated before LCM. We have retrieved sections onto both uncoated and charged slides, with similar results. Figure 8 shows an example of a cryostat section from mouse lung that was subjected to LCM. Epithelial cells were selectively removed from the four bronchioles shown in Figure 8A. The same area of the section is shown in Figure $8 \mathrm{~B}$ following LCM, revealing holes where the cells had previously been located. The captured cells retrieved onto the CapSure LCM Transfer Film cap are shown in Figure 8C. The PixCell II Image Archiving software packaged with the archiving workstation provides a simple means for assessing quality assurance and documenting the successful capture of the area intended.

Both 18S RNA and c-jun expression was detected in bronchiolar epithelial cells retrieved from mouse lung by LCM. Table 1 shows the threshold cycle $\left(C_{t}\right)$ values for expression of c-jun and 18S RNA. $\mathrm{C}_{\mathrm{t}}$ values are considered to be the PCR cycle at which an increase in reporter signal was first detected above the baseline value. cDNA generated from LCM shows a $C_{t}$ value for 18S RNA of 19.3 and a value of 33.5 for c-jun. Both of the values fall within the standard curve generated from the expression of these genes in cultured C10 cells exposed to TPA for $2 \mathrm{~h}$. Furthermore, the $\mathrm{C}_{\mathrm{t}}$ values of LCM-generated cDNA for both $18 \mathrm{~S}$ RNA and c-jun expression are well within standard accepted values. These results demonstrate our ability to use LCM, together with quantitative realtime PCR, to determine protooncogene expression in cryostat sections from mouse lung. We are now using these methods established for lung tissue to isolate epithelial cells from asbestos- 
exposed animals to determine if there is an increase in protooncogene expression in a selected cell population in response to this pathogenic mineral. We envision that the combination of LCM with quantitative real-time PCR and microarray technology will enable the genomic and proteomic analysis of specific cell populations in response to environmental stress.

\section{ACKNOWLEDGMENTS}

Quantitative real-time PCR was performed in the Vermont Cancer Center DNA Analysis Facility. We would like to thank Tim Hunter and Marylou Shane for their helpful guidance and suggestions concerning quantitative real-time PCR techniques, and Ben Millard for early assistance with LCM. Research support was provided by grant nos. R01HL39469 and R01ES/HL09213 to B.T.M. and grant nos. T32ES07122 and F32 ES05921 to C.J.P.

\section{REFERENCES}

1.Angel, P. and M. Karin. 1991.The role of Jun, Fos and the AP-1 complex in cell proliferation and transformation. Biochim. Biophys. Acta 1072:129-157.

2.Bedner, E., X. Li, W. Gorczyca, M. Melamed, and Z. Darzynkiewicz. 1999. Analysis of apoptosis by laser scanning cytometry. Cytometry 35:181-195.

3.BeruBe, K., B. Mossman, T. Quinlan, and D. Taatjes. 1998. Diverse microscopy imaging techniques for studies of asbestos-induced lung disease. Microsc. Anal. 29:13-15.

4.Bonner, R.F., M. Emmert-Buck, K. Cole, T. Pohida, R. Chuaqui, S. Goldstein, and L.A. Liotta. 1997. Laser capture microdissection: molecular analysis of tissue. Science 278:1481-1483

5.Brown, D., J. Lydon, M. McLaughlin, A. Stuart-Tilley, R. Tyszkowskin, and S. Alper. 1996. Antigen retrieval in cryostat tissue sections and cultured cells by treatment with sodium dodecyl sulfate (SDS). Histochem. Cell Biol. 105:261-267.

6.Buder-Hoffmann, S., C. Palmer, P. Vacek, D. Taatjes, and B. Mossman. 2001. Different accumulation of activated extracellular signalregulated kinases (ERK 1/2) and role in cell cycle alterations by epidermal growth factor, hydrogen peroxide or asbestos in pulmonary epithelial cells. Am. J. Respir. Cel Mol. Biol. 24:405-413.

7.Davis, W.P., Y.M.W. Janssen, B.T. Mossman, and D.J. Taatjes. 1997. Simultaneous triple fluorescence detection of mRNA localization, nuclear DNA, and apoptosis in cultured cells using confocal scanning laser mi- croscopy. Histochem. Cell Biol. 108:307-311.

8.Darzynkiewicz, Z., E. Bedner, X. Li, W. Gorczyca, and M.R. Melamed. 1999. Laser-scanning cytometry: a new instrumentation with many applications. Exp. Cell Res. 249:1-12.

9.Driscoll, K.E., J.M. Carter, P.T. Iype, H.L. Kumari, L.L. Crosby, M.J. Aardema, R.J. Isfort, D. Cody et al. 1995. Establishment of immortalized alveolar type II epithelial cell lines from adult rats. In Vitro Cell Dev. Biol. 31:516-527.

10.Emmert-Buck, M.R., R.F. Bonner, P.D. Smith, R.F. Chuaqui, Z. Zhuang, S.R. Goldstein, R.A. Weiss, and L.A. Liotta. 1996. Laser capture microdissection. Science 274:998-1001.

11.Fung, H., Y.W. Kow, B. Van Houten, D.J. Taatjes, Z. Hatahet, Y.M.W. Janssen, P. Vacek, S.P. Faux, and B.T. Mossman. 1998. Asbestos increases mammalian AP-endonuclease gene expression, protein levels, and enzyme activity in mesothelial cells. Cancer Res. 58:189-194.

12.Goldstein, S.R., P.G. McQueen, and R.F. Bonner. 1998. Thermal modeling of laser capture microdissection. Appl. Optics 37:7378-7391.

13.Goldsworthy, S.M., P.S. Stockton, C.S. Trempus, J.F. Foley, and R.R. Maronpot. 1999. Effects of fixation on RNA extraction and amplification from laser capture microdissected tissue. Mol. Carcinog. 25:86-91.

14.Kamentsky, L.A. and L.D. Kamentsky. 1991. Microscope-based multiparameter laser scanning cytometer yielding data comparable to flow cytometry data. Cytometry 12:381387.

15.Kamentsky, L.A., D.E. Burger, R.J. Gersham, L.D. Kamentsky, and E. Luther. 1997. Slide-based laser scanning cytometry. Acta. Cytol. 41:123-143.

16.Malkinson, A.M., L.D. Dwyer-Nield, P.L. Rice, and D. Dinsdale. 1997. Mouse lung epithelial cell lines-tools for the study of differentiation and the neoplastic phenotype. Toxicology 123:53-100.

17.Mossman, B.T. 1999. Environmental pathology: new directions and opportunities. Toxicol. Pathol. 27:180-186.

18.Mossman, B.T. and A. Churg. 1998. Stateof-the-art: mechanisms in the pathogenesis of asbestosis and silicosis. Am. J. Respir. Crit. Care Med. 157:1666-1680.

19.Pache, J-C., Y.M.W. Janssen, E.S. Walsh, T.R. Quinlan, C.L. Zanella, R.B. Low, D.J. Taatjes, and B.T. Mossman. 1998. Increased epidermal growth factor-receptor protein in a human mesothelial cell line in response to long asbestos fibers. Am. J. Pathol. 152:333340

20.Paddock, S.W. 2000. Confocal laser scanning microscopy. BioTechniques 27:992-1004.

21.Poynter, M.E., Y.M.W. Janssen-Heininger, S. Buder-Hoffman, D.J. Taatjes, and B.T. Mossman. 1999. Measurement of oxidant-induced signal transduction proteins using cell imaging. Free Rad. Biol. Med. 27:1164-1172.

2.Quinlan, T.R., K.A. BeruBe, M.P. Hacker, D.J. Taatjes, C.R. Timblin, J. Goldberg, P. Kimberley, P. O'Shaughnessy, D. Hemenway, J. Torino, L.A. Jimenez, and B.T. Mossman. 1998. Mechanisms of asbestos-in- duced nitric oxide production by rat alveolar macrophages in inhalation and in vitro models. Free Rad. Biol. Med. 24:778-788.

23. Robledo, R. and B. Mossman. 1999. Cellular and molecular mechanisms of asbestos-induced fibrosis. J. Cell. Physiol. 180:158-166.

24.Robledo, R.F., S.A. Buder-Hoffmann, A.B. Cummins, E.S. Walsh, D.J. Taatjes, and B.T. Mossman. 2000. Increased phosphorylated extracellular signal-regulated kinase immunoreactivity associated with proliferative and morphologic lung alterations after asbestos inhalation in mice. Am. J. Pathol 156:1307-1316

25.Simone, N.L., R.F. Bonner, J.W. Gillespie, M.R. Emmert-Buck, and L.A. Liotta. 1998. Laser capture microdissection: opening the microscopic frontier to molecular analysis. Trends Genet. 14:272-276.

26.Suarez-Quian, C.A., S.R. Goldstein, T. Pohida, P.D. Smith, J.I. Peterson, E. Wellner, M. Ghany, and R.F. Bonner. 1999. Laser capture microdissection of single cells from complex tissues. BioTechniques 26:328-335.

27.Timblin, C., K. BeruBe, A. Churg, K. Driscoll, T. Gordon, E. Walsh, A. B. Cummins, P. Vacek, and B. Mossman. 1998. Ambient particulate matter causes activation of the c-jun kinase/stress-activated protein kinase cascade and DNA synthesis in lung epithelial cells. Cancer Res. 58:4543-4547.

28.Wilson, D.M., III and C. Bianchi. 1999. Improved immunodetection of nuclear antigens after sodium dodecyl sulfate treatment of formaldehyde-fixed cells. J. Histochem. Cytochem. 47:1095-1100.

29.Zanella, C.L., J. Posada, T.R. Tritton, and B.T. Mossman. 1996. Asbestos causes stimulation of the ERK-1 mitogen-activated protein kinase cascade after phosphorylation of the epidermal growth factor receptor. Cancer Res. 56:5334-5338

30.Zanella, C.L., C.R. Timblin, A. Cummins, M. Jung, J. Goldberg, R. Raabe, T.R. Tritton, and B.T. Mossman. 1999. Asbestos-induced phosphorylation of epidermal growth factor is linked to c-fos expression and apoptosis. Am. J. Physiol. 277:L684-L693.

Address correspondence to:

Dr. Douglas J. Taatjes

Department of Pathology and Microscopy Imaging Center

Health Sciences Research Facility

University of Vermont

Burlington, VT 05405, USA

e-mail:dtaatjes@zoo.uvm.edu

For reprints of this or any other article, contact Reprints@BioTechniques.com 